\title{
Solution for Dental Cement Dosage Form
}

National Cancer Institute

\section{Source}

National Cancer Institute. Solution for Dental Cement Dosage Form. NCI Thesaurus.

Code C149905.

Liquid preparation consisting of a solution intended for use in the preparation of a dental cement. 